\title{
Endangered patients with congenital heart defect during transition-Germany-wide evaluation of medical data from National Register for Congenital Heart Defects (NRCHD)
}

\author{
Julia Remmele ${ }^{1,2} \wedge$, Sandra Schiele ${ }^{1}$, Renate Oberhoffer-Fritz ${ }^{2} \wedge$, Peter Ewert ${ }^{1,3}$, Ulrike M. M. Bauer ${ }^{4}$, \\ Paul Christian Helm ${ }^{4} \wedge$
}

${ }^{1}$ Department of Congenital Heart Disease and Pediatric Cardiology, German Heart Center Munich, Technical University of Munich, Munich, Germany; ${ }^{2}$ Institute of Preventive Pediatrics Technical University Munich, Munich, Germany; ${ }^{3}$ DZHK (German Centre for Cardiovascular Research), Partner Site Munich Heart Alliance, Munich, Germany; ${ }^{4}$ National Register for Congenital Heart Defects, DZHK (German Centre for Cardiovascular Research), Berlin, Germany

Contributions: (I) Conception and design: J Remmele, PC Helm; (II) Administrative support: R Oberhofer-Fritz, P Ewert, S Schiele; (III) Provision of study materials or patients: UMM Bauer, PC Helm; (IV) Collection and assembly of data: UMM Bauer, PC Helm, J Remmele; (V) Data analysis and interpretation: J Remmele, PC Helm, S Schiele; (VI) Manuscript writing: All authors; (VII) Final approval of manuscript: All authors.

Correspondence to: Julia Remmele, MSc. Department of Congenital Heart Disease and Pediatric Cardiology, German Heart Center Munich, Technical University of Munich, Lazarettstraße 36, 80636 München, Germany. Email: remmele@dhm.mhn.de.

\begin{abstract}
Background: Appropriate care over the entire lifespan is essential in the population with congenital heart defect since the number of patients with congenital heart defect is increasing steadily worldwide. More than $90 \%$ survive into adulthood nowadays. The transition from pediatric to adult care in patients with congenital heart defect is a major challenge in clinical practice and often fails. Patients with congenital heart defect are generally at higher risk for different acquired secondary diagnoses. This cross-sectional retrospective study analysed data from the German National Register for Congenital Heart Defects to gain insight into the clinically relevant health-status of the transition population among congenital heart defect patients in Germany.
\end{abstract}

Methods: Adolescents and young adults with congenital heart defect between the ages of 15 to 25 years (which have been defined as the transition generation) were identified using the National Register of Congenital Heart Defects medical database. Out of 55,687 patients with congenital heart defect, 8,834 adolescents and young adults with congenital heart defect [4,063 female (46.0\%); 20.3 \pm 3.1 years] were included in the statistical analyses. Statistical analyses were conducted using the student's $t$-test, $\chi^{2}$-test and Fisher's exact test.

Results: Severity of congenital heart defect: simple (23.4\%), moderate (45.1\%) and complex (31.5\%). Most common congenital heart defect: atrial septal defects (14.9\%) followed by ventricular septal defects (12.8\%) and tetralogy of Fallot (10.5\%). Most frequent acquired cardiac diagnosis: arrhythmia (25.5\%) followed by secondly pulmonary hypertension (4.5\%) and thirdly systemic arterial hypertension (3.6\%). Almost 10\% had chromosomal abnormalities and other genetic syndromes. Patients had neurological defects overall with $7.3 \%$, followed by musculoskeletal defects with $6.9 \%$ and psychological disorders with $5.6 \%$.

Conclusions: Adolescents and young adults with congenital heart defect need to bridge the gap between pediatric and adult cardiology as they already show up to 4 cardiac and up to 7 extracardiac acquired secondary diagnoses during the transition period. Otherwise, early detection of an acquired secondary diagnosis, which affects the lives of young adults with congenital heart defect, fails with all its consequences.

^ ORCID: Julia Remmele, 0000-0002-0887-3231; Renate Oberhoffer-Fritz, 0000-0002-3166-0488; Peter Ewert, 0000-0003-0253-1190; Ulrike M. M. Bauer, 0000-0002-6317-3609; Paul Christian Helm, 0000-0002-1868-4266. 
Keywords: Transition; congenital heart defect (CHD); epidemiology; health services; National Register for Congenital Heart Defects (NRCHD)

Submitted Feb 01, 2021. Accepted for publication Jul 06, 2021.

doi: $10.21037 / \mathrm{cdt}-21-66$

View this article at: https://dx.doi.org/10.21037/cdt-21-66

\section{Introduction}

As a result of improved medical treatment and care for patients with congenital heart defect (CHD), the number of CHD patients, and especially adolescent and adult patients with CHD, is increasing rapidly during the last decades (1). It was estimated in 2015 by the International Society for Adult Congenital Heart Disease (ISACHD) that worldwide, there are around 12 to 34 million adults with a congenital heart defect (ACHD) (2) and 2.3 million of them in Europe (3).

As most of the patients are not cured but palliated, appropriate and specialized CHD care during their whole lifespan is essential. A major challenge in clinical practice is their transition from pediatric to adult CHD care, since ageing CHD patients are at high risk for cardiac secondary diagnoses (SD), like arrhythmias, systemic and pulmonary arterial hypertension, thromboembolic events, infective endocarditis (4), as well as non-cardiac diseases. Many young ACHD, even with severe diagnoses, are lost to cardiological follow-up care, as they have to become responsible for their healthcare, struggle for independence, lack of compliance or knowledge, or simply move to a new environment after finishing school (5-7). Failure of the transition process may lead to delayed recognition of evolving cardiac and non-cardiac problems, which complicates subsequent patient management (6). Therefore, we need to pay special attention to this patient group reaching adulthood and becoming responsible for themselves. To improve the organisation of care for adolescents and young ACHD in Germany and to establish the right link to specialised institutions in the transition phase, it is important to know the current situation in Germany, the number of affected patients, their diagnoses and the challenges adolescents and young ACHD face. The data on young adults with CHD are continuously changing (4).

In this cross-sectional register study, we analysed data from February 2020 of adolescents and young ACHD registered in the National Register for Congenital Heart Defects (NRCHD) to obtain more detailed information on the health-related status of the transition population of adolescents and young ACHD in Germany. This study analysed data from the German NRCHD to gain insight into the clinically relevant health-status of the transition population among CHD patients in Germany. To answer the question of whether patients with CHD in Germany of transition-age are in such good health that the loss of follow-up does not pose a threat to their health or there is an urgent need for improvements. We present the following article in accordance with the STROBE reporting checklist (available at https://dx.doi.org/10.21037/cdt-21-66).

\section{Methods}

\section{NRCHD}

The NRCHD was initiated in 2003 by the three German professional associations of heart medicine [Deutsche Gesellschaft für Pädiatrische Kardiologie (DGPK), Deutsche Gesellschaft für Thorax-, Herz und Gefäßchirurgie (DGTHG), Deutsche Gesellschaft für Kardiologie (DGK)] as a non-profit, scientific association and is currently funded by the German Centre for Heart and Circulatory Research [Deutsches Zentrum für HerzKreislauf-Forschung (DZHK)]. Currently, the NRCHD has about 56,000 patients with CHD of all severity classes and age groups registered. The NRCHD is thus the largest CHD register in Europe (8). The multi-centre research approach of the NRCHD makes a nationwide retrospective and prospective representative data analysis and evaluation of CHD related medical data possible. As Helm et al. (2015) could show, the NRCHD is particularly suitable for such questions due to its representativeness (8). The established data infrastructure of the NRCHD allows data to be stored within the framework of a specific data-protection concept, which is registered with the Berlin Official for Data Protection and Freedom of Information (Nr. 531.390). General approval of the ethical review board of the Charite - Universitätsmedizin Berlin is given for all research conducted within the scope of the NRCHD.

When a child is born with CHD in Germany, the 
parents have the opportunity to register their child in the NRCHD. This registration is voluntary, free of charge and membership can be revoked at any time without stating reasons. After registration patients and relatives regularly receive information in layman's terms about the state of research in the field of CHD, and they can voluntarily participate in studies and patient surveys. They also have the opportunity to give a biospecimen (saliva, blood) so that scientists can investigate possible genetic causes of CHD. The NRCHD cooperates closely with patient organizations, resident pediatric cardiologists and cardiologists, hospitals, university clinics and special heart centres. NRCHD's medical database is based on patient data from medical reports (e.g., doctor's letters, operation reports). These medical patient data are collected by specially trained medical documentaries and medical specialists and checked for plausibility and, if necessary, corrected and regularly checked for topicality. Patients whose medical data were not classified as sufficiently secured/up-to-date at the time the data analyses were carried out were excluded from the analyses. The underlying medical documents are usually primarily cardiological medical reports. Information about, for example, drastic, non-medical or life events is only available to the NRCHD if this has also been noted in the medical records. The collected and evaluated medical data correspond to the highest standard for the evaluation of decentralized, multi-centre evidence-based data analysis.

\section{Study population}

Adolescents and young ACHD between 15 and 25 years of age (which have been defined as the transition generation) were identified using the NRCHD medical database on 12 February 2020. Out of a total of 55,687 registered patients with CHD, 11,262 (20.2\%) were identified between the age of 15-25 years [5,233 female (46.5\%)]. After deceased patients had been excluded and the clinically proven completeness of the data had been verified, 8,834 adolescents and young ACHD [4,063 female (46.0\%]] remained for statistical analysis. The Bethesda classification by Warnes et al. was used to categorise the severity of the CHD (9). The severity groups, simple, moderate and complex CHD were compared regarding the prevalence of $\mathrm{SD}$ of clinical interest across the severity groups during the transition phase.

The primary cardiac diagnosis, as well as the cardiac acquired SD, was defined and classified by using the International Paediatric and Congenital Cardiac Code
(IPCCC) (10) as well as the ICD-10 classification for extracardiac acquired diagnosis (11). The detailed classification of the CHD severity (available at https:// cdn.amegroups.cn/static/public/cdt-2020-achd-31-1.pdf), the IPCCC diagnoses (available at https://cdn.amegroups. cn/static/public/cdt-2020-achd-31-2.pdf) and the ICD10 diagnoses (available at https://cdn.amegroups.cn/ static/public/cdt-2020-achd-31-3.pdf) can be found in the Appendix. In the context of this work, the term acquired SD serves as an overarching term that includes sequelae, residual disease as well as comorbidities.

\section{Statistical analyses}

For categorical variables, descriptive statistics were calculated in absolute and relative frequencies (\%), in numerical variables means and standard deviations. The Shapiro-Wilk test was used to test for normal distribution and group comparison was performed using student's $t$-test, $\chi^{2}$-test as well as Fisher's exact test.

Alpha error adjustment in multiple comparisons was not performed due to the explorative and descriptive nature of the study, and to avoid overlooking potential influencing factors (12). Statistical analyses were conducted using the software SPSS V.25 (SPSS Inc., Chicago, Illinois, USA). The level of statistical significance was determined twosided and with a $\mathrm{P}$ value $<0.05$.

\section{Results}

The majority of adolescents and young ACHD were of moderate CHD severity (45.1\%) followed by complex CHD (31.5\%) and simple CHD (23.4\%), with a close to an identical mean age of $20.3 \pm 3.1$ years (Table 1). Female overall accounted for 4,063 (46.0\%) adolescents and young ACHD with significantly more female patients in the simple CHD group (55.9\%) compared to the moderate (45.9\%) and complex $(38.7 \%)$ severity groups $(\mathrm{P}<0.001)$. Overall, the most common defects were $1,317(14.9 \%)$ atrial septal defects (ASD) followed by 1,129 (12.8\%) ventricular septal defects (VSD) then 929 (10.5\%) tetralogy of Fallot (TOF). The most common CHD diagnoses in patients with simple CHD was ASD (36.4\%), coarctation of the artery (CoA) $(18.1 \%)$ in patients with moderate CHD and univentricular heart $(\mathrm{UVH})(26.0 \%)$ in the complex CHD patient group (Table 1).

Further details on surgical and interventional procedures are shown in Table 1. Regarding structural heart defect 
Table 1 Descriptive data of the transition generation of CHD patients in Germany

\begin{tabular}{|c|c|c|c|c|c|c|c|}
\hline Variable & $\begin{array}{l}\text { Total number of } \\
\text { patients }\end{array}$ & $\begin{array}{l}\text { Simple severity } \\
\text { by Warnes et al. }\end{array}$ & $\begin{array}{l}S \text { vs. } M \\
P \text { value }\end{array}$ & $\begin{array}{l}\text { Moderate severity } \\
\text { by Warnes et al. }\end{array}$ & $\begin{array}{l}\mathrm{M} \text { vs. } \mathrm{C} \\
\mathrm{P} \text { value }\end{array}$ & $\begin{array}{l}\text { Complex severity } \\
\text { by Warnes et al. }\end{array}$ & $\begin{array}{l}\mathrm{S} \text { vs. } \mathrm{C} \\
\mathrm{P} \text { value }\end{array}$ \\
\hline Number of Patients & 8,834 & $2,067(23.4 \%)$ & - & $3,987(45.1 \%)$ & - & $2,780(31.5 \%)$ & - \\
\hline Sex, female (\%) & 4,063 (46.0\%) & $1,156(55.9 \%)$ & $<0.001^{\#}$ & $1,832(45.9 \%)$ & $<0.001^{\#}$ & $1,075(38.7 \%)$ & $<0.001^{\#}$ \\
\hline $\begin{array}{l}\text { Most frequent } \\
\text { CHD-diagnoses } \\
\text { (>10\% of the group) }\end{array}$ & $\begin{array}{c}\text { VSD: } 1,317(14.9 \%) ; \\
\text { ASD: } 1,129(12.8 \%) ; \\
\text { TOF: } 929(10.5 \%)\end{array}$ & $\begin{array}{l}\text { ASD: } 735 \text { (36.4\%); } \\
\text { VSD: } 615(29.8 \%) ; \\
\text { AoV: } 252(12.2 \%)\end{array}$ & - & $\begin{array}{l}\text { CoA: } 723 \text { (18.1\%); } \\
\text { VSD: } 577(14.5 \%) ; \\
\text { AVSD: } 429(10.8 \%)\end{array}$ & - & $\begin{array}{l}\text { UVH: } 722 \text { (26.0\%); } \\
\text { TGA: } 605 \text { (21.8\%); } \\
\text { TOF: } 504 \text { (18.1\%) }\end{array}$ & - \\
\hline Number of surgeries ${ }^{a}$ & $3.3 \pm 2.7(1 / 22)$ & $1.3 \pm 0.6(1 / 3)$ & $<0.001^{\#}$ & $2.3 \pm 1.7(1 / 22)$ & $<0.001^{\#}$ & $4.6 \pm 3.0(1 / 22)$ & $<0.001^{\#}$ \\
\hline Age at first surgery & $2.0 \pm 3.0$ & $3.7 \pm 3.7$ & $<0.001^{\#}$ & $2.7 \pm 4.4$ & $<0.001^{\#}$ & $1.2 \pm 3.2$ & $<0.001^{\#}$ \\
\hline $\begin{array}{l}\text { Number of catheter } \\
\text { interventions }{ }^{a}\end{array}$ & $2.1 \pm 2.1(1 / 24)$ & $1.1 \pm 0.3(1 / 3)$ & $<0.001^{\#}$ & $1.5 \pm 1.2(1 / 24)$ & $<0.001^{\#}$ & $2.8 \pm 2.6(1 / 24)$ & $<0.001^{\#}$ \\
\hline Prematurity & $339(3.8 \%)$ & $82(4.0 \%)$ & 0.804 & $153(3.8 \%)$ & 0.838 & $104(3.7 \%)$ & 0.685 \\
\hline
\end{tabular}

*, Appendix A (available at https://cdn.amegroups.cn/static/public/cdt-2020-achd-31-1.pdf) with detailed information on the classification by Warnes et al.; " , following the definition of the International Paediatric and Congenital Cardiac Code (IPCCC); \#, P<0.05. CHD, congenital heart defect; S, simple; M, moderate; C, complex; P, level of significance with $\mathrm{P} \leq 0.05$; VSD, ventricular septum defect; ASD, atrial septum defect; CoA, coarctation of the artery; UVH, univentricular heart; TGA, transposition of the great arteries; AoV, aortic valve stenosis; AVSD, atrioventricular septal defect; TOF, tetralogy of Fallot.

groups, septal defects/vascular malformations showed $40.6 \%$ the highest proportion followed by left heart obstruction with $19.7 \%$ overall (Table 2). An accurate allocation of heart defect groups adapted from Schumacher et al. can be found in Appendix B (available at https://cdn.amegroups.cn/static/ public/cdt-2020-achd-31-2.pdf) (13).

As shown in Table 1, there was no difference in the severity of CHD in preterm births.

Almost 9.4\% [832] of the patients had chromosomal abnormalities and other genetic syndromes, with trisomy $21(55.5 \%)$ being the most frequent, followed by DiGeorge syndrome (Table 3).

\section{Cardiac acquired SD}

The most frequent cardiac acquired SD was arrhythmia with 2,225 $(25.5 \%)$ cases in the transition group and with a frequency that more than doubles from severity class to severity class (Table 3). With $43.8 \%$ arrhythmia occurred the most often in the right heart obstruction group followed by patients with UVH 35.6\% (Table 2).

Secondly, pulmonary hypertension occurred in 401 $(4.5 \%)$ cases and thirdly systemic arterial hypertension in $316(3.6 \%)$ adolescents and young ACHD. Concerning pulmonary hypertension highest prevalence was shown in patients with septal defects/vascular malformation at $6.9 \%$ followed by UVH patients at $6.0 \%$. Systemic arterial hypertension showed the highest prevalence in patients with left heart obstruction at $11.3 \%$ followed by UVH patients at $4.0 \%$ (Table 2).

\section{Extracardiac acquired $S D$}

In extracardiac acquired SD patients had neurological SD overall in $643(7.3 \%)$ cases, followed by musculoskeletal SD with 607 (6.9\%) and psychological SD with 497 (5.6\%). Further details on extracardiac acquired SD are shown in Table 3. The highest prevalence of extracardiac acquired SD were shown in UVH patients in all analysed aspects except in metabolic SD left heart obstruction patients had a higher prevalence, in "ear, nose and throat" SD had a higher prevalence in patients with right heart obstruction, and "lung" SD in patients with "other" as defect group (Table 2).

Figure 1 shows the cardiac acquired SD with their prevalence among the CHD severity classes with a frequency of up to 4 cardiac acquired SD. Figure 2 shows the prevalence of extracardiac acquired SD among the severity classes and a frequency of up to 7 extracardiac 
Table 2 Prevalence of extracardiac and cardiac acquired secondary diagnoses according to heart defect groups*

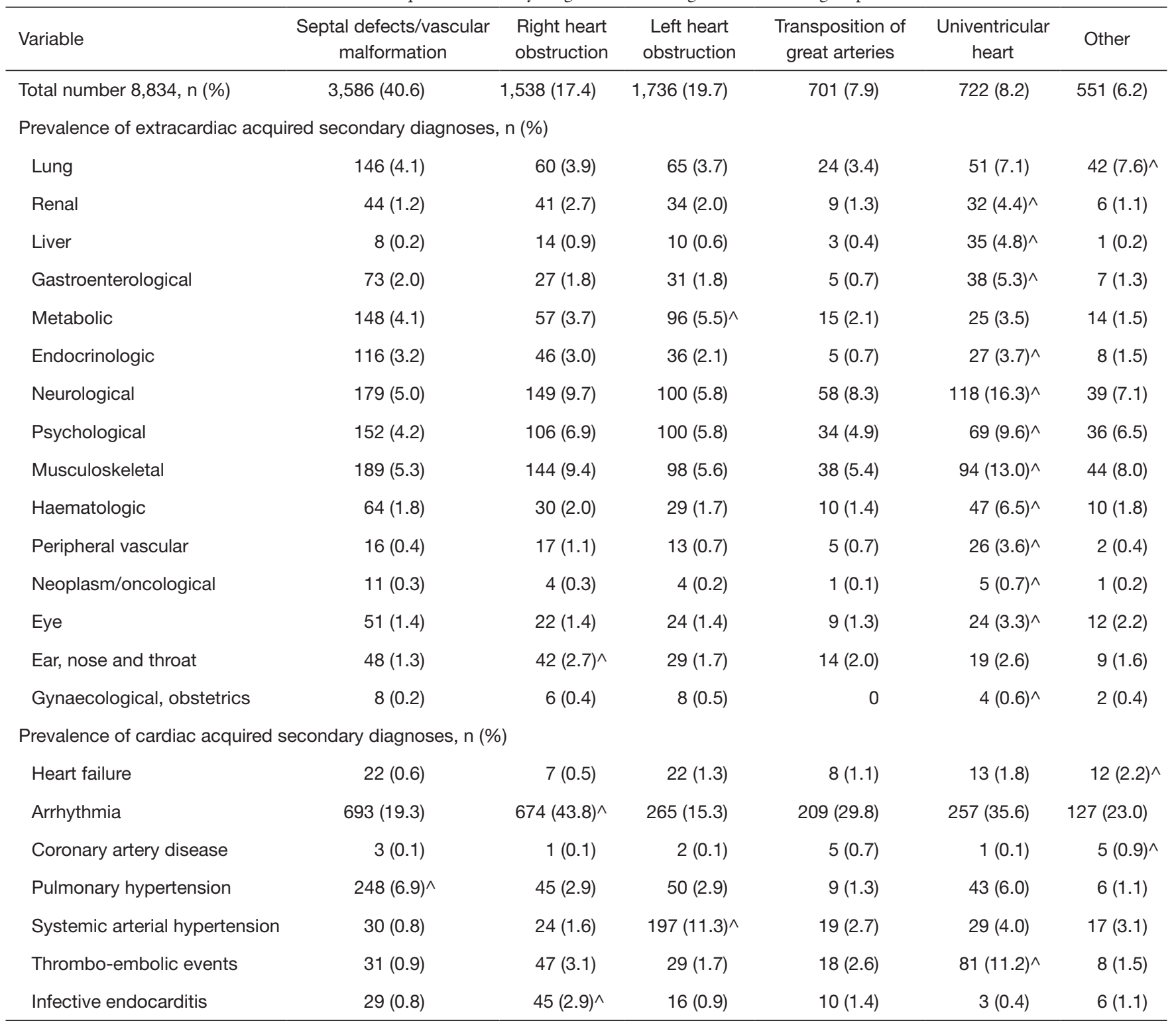

*, the one-to-one classification according to the IPCCC can be found in Appendix B (available at https://cdn.amegroups.cn/static/public/ cdt-2020-achd-31-2.pdf); ^, the highest prevalence rates. IPCCC, International Paediatric and Congenital Cardiac Code.

acquired SD.

\section{Discussion}

An estimated 1.35-1.5 million children worldwide are born with CHD every year, $45 \%$ of them with moderate or complex CHD, 55\% with simple CHD (14). All kinds of CHD increased in adults to $55 \%$ of all patients with CHD from the year 2000 to 2010 in Quebec with an increased prevalence of severe CHD (1). In our present nationwide study, results for Germany show a larger proportion of adolescents and young ACHD in the moderate and complex severity class of CHD than in the simple heart defects group. Plausible reasons for the increased prevalence of severe CHD in adolescents and young adults are improvements in diagnostic procedures, interventional and medical treatments that have led to reduced mortality in recent decades. 
Table 3 Prevalence of acquired secondary diagnoses in the CHD transition population

\begin{tabular}{|c|c|c|c|c|c|c|c|}
\hline Diagnoses & $\begin{array}{c}\text { Total number } \\
\text { of patients } \\
(n=8,834)\end{array}$ & $\begin{array}{c}\text { Simple } \\
\text { severity } \\
(n=2,067)\end{array}$ & $\begin{array}{l}S \text { vs. } M \\
P \text { value }\end{array}$ & $\begin{array}{c}\text { Moderate } \\
\text { severity } \\
(n=3,987)\end{array}$ & $\begin{array}{l}M \text { vs. } C \\
P \text { value }\end{array}$ & $\begin{array}{c}\text { Complex } \\
\text { severity } \\
(n=2,780)\end{array}$ & $\begin{array}{l}S \text { vs. } C \\
P \text { value }\end{array}$ \\
\hline \multicolumn{8}{|l|}{ Acquired cardiac diagnoses, $\mathrm{n}(\%)$} \\
\hline Heart failure & $84(1.0)$ & 0 & $<0.001^{\#}$ & $37(0.9)$ & $0.005^{\#}$ & $47(1.7)$ & $<0.001^{\#}$ \\
\hline Arrhythmia & $2,225(25.5)$ & $185(9.0)$ & $<0.001^{\#}$ & $873(21.9)$ & $<0.001^{\#}$ & $1,167(42.0)$ & $<0.001^{\#}$ \\
\hline Pulmonary hypertension & $401(4.5)$ & 0 & $0.001^{\#}$ & $23(0.6)$ & $<0.001^{\#}$ & $378(13.6)$ & $<0.001^{\#}$ \\
\hline Systemic arterial hypertension & $316(3.6)$ & $15(0.7)$ & $<0.001^{\#}$ & $202(5.1)$ & $0.003^{\#}$ & $99(3.6)$ & $<0.001^{\#}$ \\
\hline Thrombo-embolic events & $214(2.4)$ & $4(0.2)$ & $<0.001^{\#}$ & $45(1.1)$ & $<0.001^{\#}$ & $165(5.9)$ & $<0.001^{\#}$ \\
\hline Infective endocarditis & $109(1.2)$ & 0 & $0.011^{\text {a\# }}$ & $12(0.3)$ & $<0.001^{\#}$ & $97(3.5)$ & $<0.001^{\#}$ \\
\hline Trisomy 21 & $462(55.5)$ & $74(64.9)$ & - & $275(57.9)$ & - & $113(46.5)$ & - \\
\hline DiGeorge 22q11 & $138(16.6)$ & $5(4.4)$ & - & $53(11.2)$ & - & 80 (32.9) & - \\
\hline Williams-Beuren & $39(4.7)$ & $1(0.9)$ & - & $36(7.6)$ & - & $2(0.8)$ & - \\
\hline Noonan & $35(4.2)$ & $5(4.4)$ & - & $27(5.7)$ & - & $3(1.2)$ & - \\
\hline Other & $158(19.0)$ & $29(25.4)$ & - & $84(17.7)$ & - & $45(18.5)$ & - \\
\hline \multicolumn{8}{|c|}{ Acquired extracardiac diagnoses*, n (\%) } \\
\hline Lung & $388(4.4)$ & $57(2.8)$ & $0.013^{\#}$ & $160(4.0)$ & $<0.001^{\#}$ & $171(6.2)$ & $<0.001^{\#}$ \\
\hline Peripheral vascular & $79(0.9)$ & $1(0.1)$ & $0.004^{\#}$ & $20(0.5)$ & $<0.001^{\#}$ & $58(2.1)$ & $<0.001^{\#}$ \\
\hline Neoplasm/oncological & $26(0.3)$ & $8(0.4)$ & 0.356 & $10(0.3)$ & 0.772 & $8(0.3)$ & 0.551 \\
\hline Neurological & $643(7.3)$ & $67(3.2)$ & $<0.001^{\#}$ & $229(5.7)$ & $<0.001^{\#}$ & $347(12.5)$ & $<0.001^{\#}$ \\
\hline Psychological & $497(5.6)$ & $73(3.5)$ & $0.007^{\#}$ & $202(5.1)$ & $<0.001^{\#}$ & $222(8.0)$ & $<0.001^{\#}$ \\
\hline Gynaecological, obstetrics & $28(0.3)$ & $4(0.2)$ & $0.783^{\mathrm{a}}$ & $10(0.3)$ & 0.098 & $14(0.5)$ & 0.079 \\
\hline Musculoskeletal & $607(6.9)$ & $72(3.5)$ & $<0.001^{\#}$ & $229(5.7)$ & $<0.001^{\#}$ & $306(11.0)$ & $<0.001^{\#}$ \\
\hline Haematological & $190(2.2)$ & $29(1.4)$ & 0.934 & $57(1.4)$ & $<0.001^{\#}$ & $104(3.7)$ & $<0.001^{\#}$ \\
\hline Ear, nose and throat & $161(1.8)$ & $22(1.1)$ & 0.068 & $66(1.7)$ & $0.006^{\#}$ & $73(2.6)$ & $<0.001^{\#}$ \\
\hline Eye & $142(1.6)$ & $26(1.3)$ & 0.816 & $53(1.3)$ & $0.003^{\#}$ & $63(2.3)$ & $0.010^{\#}$ \\
\hline
\end{tabular}

*, Appendix C (available at https://cdn.amegroups.cn/static/public/cdt-2020-achd-31-3.pdf) with detailed allocation based on ICD-10 categorization; ' , the expected value was below 5, therefore, the Fischer's exact test was used instead of $\chi^{2}$; \#, P<0.05. n, number; CHD, congenital heart defect; $\mathrm{S}$, simple; $\mathrm{M}$, moderate; C, complex; $\mathrm{P}$, level of significance with $\mathrm{P} \leq 0.05$. 


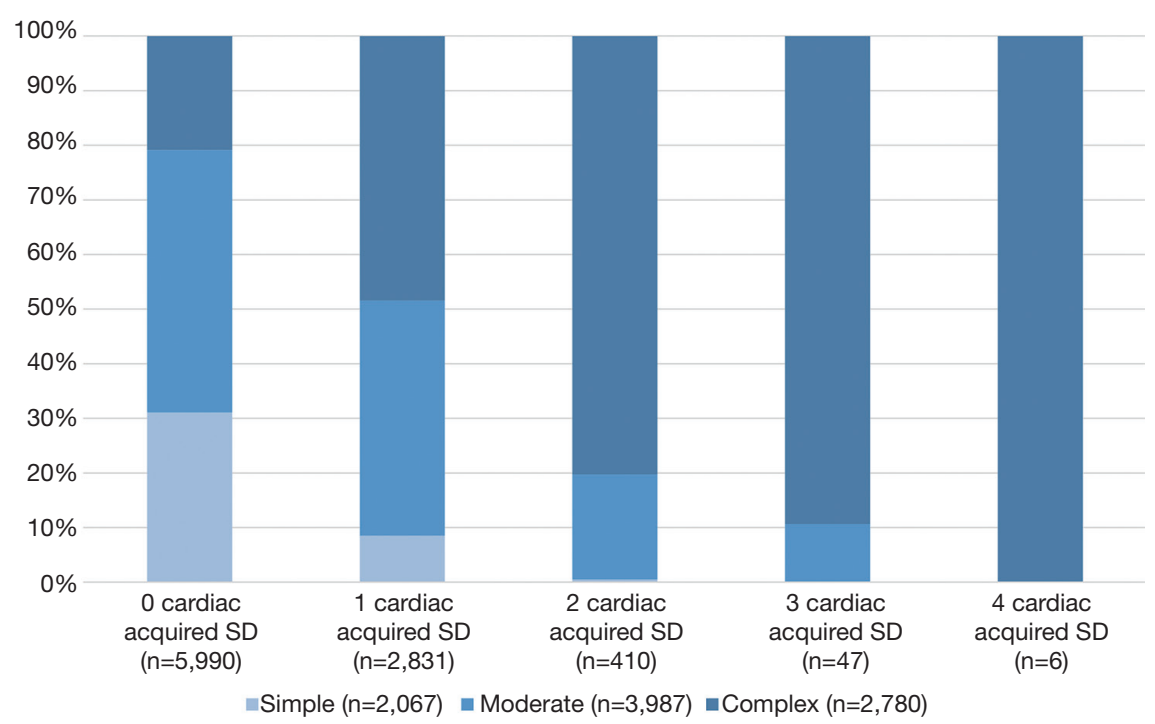

Figure 1 Distribution of cardiac acquired secondary diagnoses within the CHD severity class displayed in percentages. SD, secondary diagnosis; n, number; CHD, congenital heart defect.

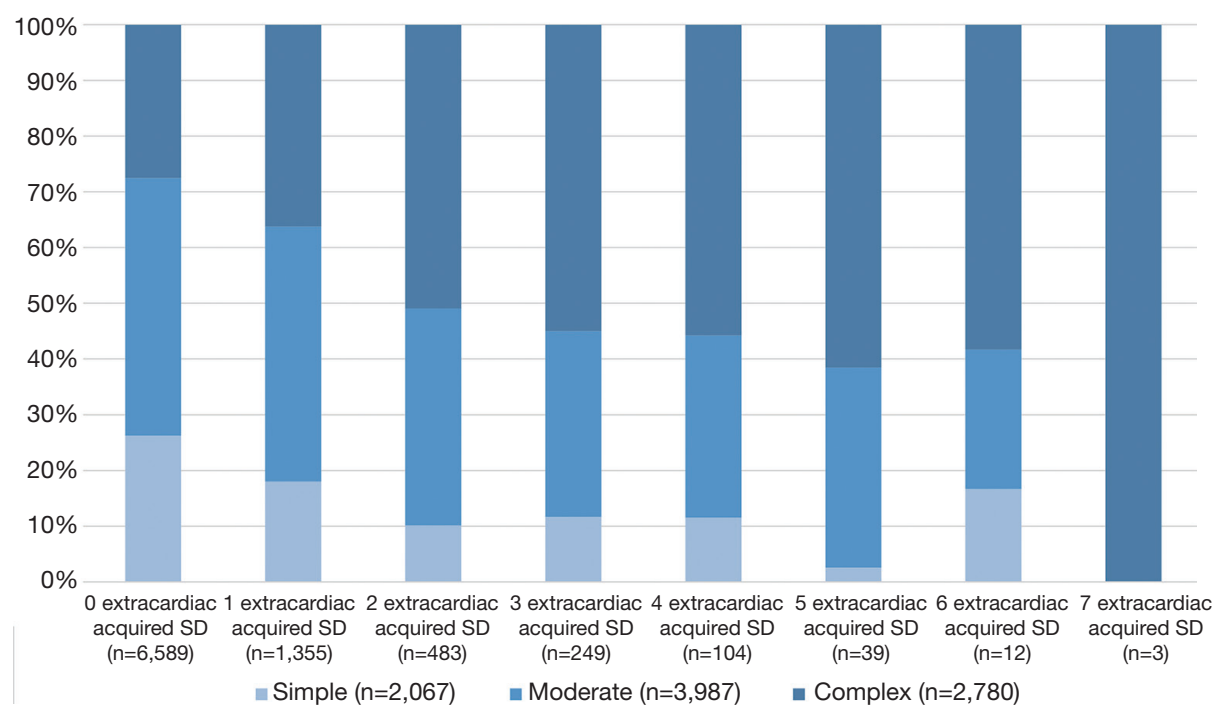

Figure 2 Distribution of extracardiac acquired secondary diagnoses within the CHD severity class displayed in percentages. SD, secondary diagnosis; n, number; CHD, congenital heart defect.

Regarding preterm birth rates, there is an increase during the last decades in Europe (15) which accounts for $5-12 \%$. CHD is one of the most frequent malformation causing preterm birth with two times higher frequency than full-term infants (16). Therefore, we decided to include this clinical parameter in the baseline characteristics. Interestingly, in our study population, there was no difference in the preterm birth rates between the different severity groups. With about $4 \%$, the preterm birth rate was even lower than in the normal German population [1990: $7.2 \%, 2010: 8.6 \%$; (17)].

\section{Cardiac acquired $S D$}

In our transition group, even though the patient cohort was still young, more than a quarter of all investigated 
patients had arrhythmia. Arrhythmias were significantly increased from $9 \%$ in simple CHD to $42 \%$ in adolescents and young ACHD with complex CHD. The largest proportion of arrhythmia patients occurred in the group of right heart obstruction CHD (43.8\%) followed by patients with univentricular circulation (35.6\%). The majority of patients showed a complete right bundle branch block (42.3\%) followed by 1 st degree atrioventricular block (9.8\%). Arrhythmias are known to be the main reason for the hospitalization of ACHD and they are an increasingly frequent cause of mortality $(18,19)$.

Cardiac acquired SD, such as coronary artery disease and heart failure, are quite important to treat adequately, as they often occur in ACHD (20) and are strong predictors of poor outcome (21). But not in our transition group, this may depend on these cardiac acquired SDs occur in older ages. Whereas almost $14 \%$ with complex CHD was suffering from pulmonary hypertension. In our study, thrombo-embolic events and infective endocarditis occurred significantly more often, the higher the severity class. In summary, in patients with simple CHD, the most important cardiac acquired SD is arrhythmia. Whereas all other cardiac acquired diagnoses we investigated were not relevant for this patient group at this age or rather, they lead to the patients moving to higher severity class, e.g., development of Eisenmenger syndrome (9).

Patients with complex CHD do have more cardiac acquired diagnoses even at an adolescent age, the most frequent still being arrhythmia. However, even in this patient group, pulmonary hypertension, thromboembolic events, systemic arterial hypertension and infective endocarditis are relevant cardiac acquired SD (Figure 1).

\section{Extracardiac acquired SD}

It was investigated whether extracardiac acquired SD already play a role in adolescents and young ACHD going through the transition period. Common extracardiac acquired SD in ACHD are renal disease (22), lung disease (23), liver disease, neoplasms (catheter- and imaging-related), as well as psychological (anxiety, depression, neurocognitive delays) and pregnancy-related issues (24). Regarding the extracardiac acquired SD in our transition group, the most common acquired diagnoses of the adolescent and young ACHD involved the neurological (7.3\%) or musculoskeletal (6.9\%) system (both including developmental delays).

With the third-highest proportion of extracardiac acquired SD, psychological disorders, including neurocognitive delays
(5.6\%), are significant for adolescent and young ACHD followed by the lungs and the metabolic system.

Whereas gynecologic and obstetrical issues are known to be important problems for females with CHD (25), they didn't play a major role in our transition group. The young age of our transition group could be one reason, as obstetric problems do not occur until the first birth in the mid-20s to 30s (26). Almost all acquired extracardiac acquired SD became more frequent, the higher the severity class.

As Table 2 shows patients with UVH presenting the highest prevalence in close to all extracardiac acquired SD. Except in metabolic SD, the group of left-heart obstructions showed the highest prevalence. Neidenbach et al. (2018), in their study cohort of ACHD with an age range of 15.5 to 80.0 years, reported metabolic comorbidities in $44 \%$ ACHD (25). This is in strong contrast to our younger transition group with a prevalence of $4 \%$ overall. This implies that the transition age plays an increasingly important role, as it is the chance to avoid this $40 \%$ increase in metabolic diseases.

Fortunately, oncological diseases were rare in our transition group and their prevalence did not vary between the CHD severity classes. A recent NRCHD-register study from 2016 showed that malignancies were the cause of death in $5 \%$ of ACHD (27), but in our study, the age range was limited due to the focus on transition-aged CHD patients. Another reason for the low incidence of oncological SD is the fact that most patients possibly develop thyroid cancer later than 20 years after exposure to low-dose radiation (28).

Concerning extracardiac acquired SD, it can be summarised that; on the one hand, the transition group under consideration already had up to seven extracardiac acquired SD (Figure 2). Also, the transition group showed most of the extracardiac acquired SD, which mostly occur in older age, lower prevalent, but existing. Especially neurological SD often occur in combination with psychological components and musculoskeletal limitations. For other extracardiac acquired SD especially in metabolic diseases, the transition age seems to be an important approach for preventive strategies to avoid a loss to follow-up.

The current medical care situation in Germany was investigated in 2017 by a survey in ACHD; most of the patients stated that they were mainly treated by an ACHD clinic $(25 \%)$, a pediatric cardiologist in private practice $(33 \%)$, or an adult cardiologist in private practice $(32 \%)$. But there were almost $10 \%$ of the surveyed patients were not treated by any of the former physicians for their CHD. In the group of simple CHD, this number even went up to 
$18 \%$ (29). Seidel et al. were also found to report very similar results in a recent publication in 2020 (30). Our study data prove that there is a need for structured programmes that enable and/or ensure a successful transition as was recommended in the latest European Society of Cardiology (ESC) guidelines on ACHD (31). There are transition projects around the world, e.g., structured education programs (32), nurse-led interventions improving CHD knowledge (33) or the development of a mobile app to reach children and young adults (34), and they show promising results. Further development to establish a smooth and well-functioning transition process in Germany is still needed.

\section{Conclusions}

As this NRCHD analysis showed, adolescents and young ACHD had up to four cardiac acquired SD and up to seven extracardiac acquired SD. These findings show the clinical relevance of this transition phase for adolescents and young ACHD and underlines the importance of this age as a suitable starting point for targeted prevention strategies. For adolescents and young ACHD, there is an urgent need to bridge the gap between paediatric and adult cardiology and to find sustainable strategies to not lose these young patients in this transitional phase. Otherwise, early detection of acquired SD, which affects the lives of adolescents and young ACHD, will fail with all its consequences.

\section{Limitations}

Due to the registration process of the NRCHD, we included only patients with clinically apparent CHD and available medical data. This may lead to an underrepresentation of simple, clinical unapparent CHD and we cannot rule out that the rate of moderate and complex CHD is overestimated.

This study is a cross-sectional retrospective registry study, therefore, relations of cause and effect cannot be concluded. As previous studies also showed differences due to study setting and location, the results should be generalized to patients beyond Germany only with caution.

\section{Acknowledgments}

Our sincere thanks go to all patients and parents registered in the National Register for Congenital Heart Defects. The authors also thank Leon Brudy for language proof. German
Competence Network for Congenital Heart Defects Investigators (available at https://cdn.amegroups.cn/static/ public/cdt-2020-achd-31-4.pdf).

Funding: This work was supported by the Competence Network for Congenital Heart Defects, which has received funding from the Federal Ministry of Education and Research, grant number 01GI0601 (until 2014), and the DZHK (German Centre for Cardiovascular Research; as of 2015).

\section{Footnote}

Provenance and Peer Review: This article was commissioned by the Guest Editors (Yskert von Kodolitsch, Harald Kaemmerer, Koichiro Niwa) for the series "Current Management Aspects in Adult Congenital Heart Disease (ACHD): Part IV" published in Cardiovascular Diagnosis and Therapy. The article has undergone external peer review.

Reporting Checklist: The authors have completed the STROBE reporting checklist. Available at https://dx.doi. org/10.21037/cdt-21-66

Conflicts of Interest: All authors have completed the ICMJE uniform disclosure form (available at https://dx.doi. org/10.21037/cdt-21-66). The series "Current Management Aspects in Adult Congenital Heart Disease (ACHD): Part IV" was commissioned by the editorial office without any funding or sponsorship. The authors have no other conflicts of interest to declare.

Ethical Statement: The authors are accountable for all aspects of the work in ensuring that questions related to the accuracy or integrity of any part of the work are appropriately investigated and resolved. NRCHD specific data-protection concept is registered with the Berlin Official for Data Protection and Freedom of Information (Nr. 531.390). General approval of the Ethical Review Board of the Charité - Universitätsmedizin Berlin is given for all research conducted within the scope of the NRCHD.

Open Access Statement: This is an Open Access article distributed in accordance with the Creative Commons Attribution-NonCommercial-NoDerivs 4.0 International License (CC BY-NC-ND 4.0), which permits the noncommercial replication and distribution of the article with the strict proviso that no changes or edits are made and the original work is properly cited (including links to both the 
formal publication through the relevant DOI and the license). See: https://creativecommons.org/licenses/by-nc-nd/4.0/.

\section{References}

1. Marelli AJ, Ionescu-Ittu R, Mackie AS, et al. Lifetime prevalence of congenital heart disease in the general population from 2000 to 2010. Circulation 2014;130:749-56.

2. Webb G, Mulder BJ, Aboulhosn J, et al. The care of adults with congenital heart disease across the globe: Current assessment and future perspective: A position statement from the International Society for Adult Congenital Heart Disease (ISACHD). Int J Cardiol 2015;195:326-33.

3. Moons P, Meijboom FJ, Baumgartner H, et al. Structure and activities of adult congenital heart disease programmes in Europe. Eur Heart J 2010;31:1305-10.

4. Baumgartner H, Bonhoeffer P, De Groot NM, et al. ESC Guidelines for the management of grown-up congenital heart disease (new version 2010). Eur Heart J 2010;31:2915-57.

5. Mackie AS, Ionescu-Ittu R, Therrien J, et al. Children and adults with congenital heart disease lost to follow-up: who and when? Circulation 2009;120:302-9.

6. Baumgartner $\mathrm{H}$, Budts $\mathrm{W}$, Chessa $\mathrm{M}$, et al. Recommendations for organization of care for adults with congenital heart disease and for training in the subspecialty of 'Grown-up Congenital Heart Disease' in Europe: a position paper of the Working Group on Grown-up Congenital Heart Disease of the European Society of Cardiology. Eur Heart J 2014;35:686-90.

7. Wacker A, Kaemmerer H, Hollweck R, et al. Outcome of operated and unoperated adults with congenital cardiac disease lost to follow-up for more than five years. Am J Cardiol 2005;95:776-9.

8. Helm PC, Koerten MA, Abdul-Khaliq H, et al. Representativeness of the German National Register for Congenital Heart Defects: a clinically oriented analysis. Cardiol Young 2016;26:921-6.

9. Warnes CA, Williams RG, Bashore TM, et al. ACC/ AHA 2008 guidelines for the management of adults with congenital heart disease: a report of the American College of Cardiology/American Heart Association Task Force on Practice Guidelines (Writing Committee to Develop Guidelines on the Management of Adults With Congenital Heart Disease). Developed in Collaboration With the American Society of Echocardiography, Heart Rhythm Society, International Society for Adult Congenital Heart
Disease, Society for Cardiovascular Angiography and Interventions, and Society of Thoracic Surgeons. J Am Coll Cardiol 2008;52:e143-263.

10. Franklin RC, Jacobs JP, Krogmann ON, et al. Nomenclature for congenital and paediatric cardiac disease: historical perspectives and The International Pediatric and Congenital Cardiac Code. Cardiol Young 2008;18 Suppl 2:70-80.

11. World Health Organization. International statistical classification of diseases and related health problems: 10th revision (ICD-10). 1992. Available online: http://www. who.int/classifications/apps/icd/icd

12. Bonferroni C. Teoria statistica delle classi e calcolo delle probabilita. Pubblicazioni del R Istituto Superiore di Scienze Economiche e Commericiali di Firenze 1936;8:3-62.

13. Schumacher G, Hess J, Bühlmeyer K. Klinische Kinderkardiologie: Diagnostik und Therapie der angeborenen Herzfehler. 4th edition. Berlin: Germany: Springer-Verlag, 2008.

14. van der Linde D, Konings EE, Slager MA, et al. Birth prevalence of congenital heart disease worldwide: a systematic review and meta-analysis. J Am Coll Cardiol 2011;58:2241-7.

15. Zeitlin J, Szamotulska K, Drewniak N, et al. Preterm birth time trends in Europe: a study of 19 countries. BJOG 2013;120:1356-65.

16. Tanner K, Sabrine N, Wren C. Cardiovascular malformations among preterm infants. Pediatrics 2005; 116:e833-8.

17. Blencowe H, Cousens S, Oestergaard MZ, et al. National, regional, and worldwide estimates of preterm birth rates in the year 2010 with time trends since 1990 for selected countries: a systematic analysis and implications. Lancet 2012;379:2162-72.

18. Khairy P, Van Hare GF, Balaji S, et al. PACES/HRS Expert Consensus Statement on the Recognition and Management of Arrhythmias in Adult Congenital Heart Disease: developed in partnership between the Pediatric and Congenital Electrophysiology Society (PACES) and the Heart Rhythm Society (HRS). Endorsed by the governing bodies of PACES, HRS, the American College of Cardiology (ACC), the American Heart Association (AHA), the European Heart Rhythm Association (EHRA), the Canadian Heart Rhythm Society (CHRS), and the International Society for Adult Congenital Heart Disease (ISACHD). Heart Rhythm 2014;11:e102-65.

19. Kumar S, Tedrow UB, Triedman JK. Arrhythmias in Adult 
Congenital Heart Disease: Diagnosis and Management.

Cardiol Clin 2015;33:571-88, viii.

20. Bauer UMM, Körten MA, Diller GP, et al. Cardiovascular risk factors in adults with congenital heart defects Recognised but not treated? An analysis of the German National Register for Congenital Heart Defects. Int J Cardiol 2019;277:79-84.

21. Tutarel O, Kempny A, Alonso-Gonzalez R, et al. Congenital heart disease beyond the age of 60 : emergence of a new population with high resource utilization, high morbidity, and high mortality. Eur Heart J 2014;35:725-32.

22. Dimopoulos K, Diller GP, Koltsida E, et al. Prevalence, predictors, and prognostic value of renal dysfunction in adults with congenital heart disease. Circulation 2008;117:2320-8.

23. Alonso-Gonzalez R, Borgia F, Diller GP, et al. Abnormal lung function in adults with congenital heart disease: prevalence, relation to cardiac anatomy, and association with survival. Circulation 2013;127:882-90.

24. Everitt IK, Gerardin JF, Rodriguez FH 3rd, et al. Improving the quality of transition and transfer of care in young adults with congenital heart disease. Congenit Heart Dis 2017;12:242-50.

25. Neidenbach RC, Lummert E, Vigl M, et al. Non-cardiac comorbidities in adults with inherited and congenital heart disease: report from a single center experience of more than 800 consecutive patients. Cardiovasc Diagn Ther 2018;8:423-31.

26. Voigt M, Rochow N, Zygmunt M, et al. Risks of pregnancy and birth, birth presentation, and mode of

Cite this article as: Remmele J, Schiele S, Oberhoffer-Fritz R, Ewert P, Bauer UMM, Helm PC. Endangered patients with congenital heart defect during transition-Germanywide evaluation of medical data from National Register for Congenital Heart Defects (NRCHD). Cardiovasc Diagn Ther 2021;11(6):1284-1294. doi: 10.21037/cdt-21-66 delivery in relation to the age of primiparous women. $Z$ Geburtshilfe Neonatol 2008;212:206-10.

27. Engelings CC, Helm PC, Abdul-Khaliq H, et al. Cause of death in adults with congenital heart disease - An analysis of the German National Register for Congenital Heart Defects. Int J Cardiol 2016;211:31-6.

28. Lubin JH, Adams MJ, Shore R, et al. Thyroid Cancer Following Childhood Low-Dose Radiation Exposure: A Pooled Analysis of Nine Cohorts. J Clin Endocrinol Metab 2017;102:2575-83.

29. Helm PC, Kaemmerer H, Breithardt G, et al. Transition in Patients with Congenital Heart Disease in Germany: Results of a Nationwide Patient Survey. Front Pediatr 2017;5:115.

30. Seidel L, Nebel K, Achenbach S, et al. Facts about the General Medical Care of Adults with Congenital Heart Defects: Experience of a Tertiary Care Center. J Clin Med 2020;9:1943.

31. Baumgartner H, De Backer J. The ESC Clinical Practice Guidelines for the Management of Adult Congenital Heart Disease 2020. Eur Heart J 2020;41:4153-4.

32. de Hosson M, De Backer J, De Wolf D, et al. Development of a transition program for adolescents with congenital heart disease. Eur J Pediatr 2020;179:339-48.

33. Mackie AS, Rempel GR, Kovacs AH, et al. Transition Intervention for Adolescents With Congenital Heart Disease. J Am Coll Cardiol 2018;71:1768-77.

34. Lopez KN, O'Connor M, King J, et al. Improving Transitions of Care for Young Adults With Congenital Heart Disease: Mobile App Development Using Formative Research. JMIR Form Res 2018;2:e16. 